\section{From Editor-in-Chief}

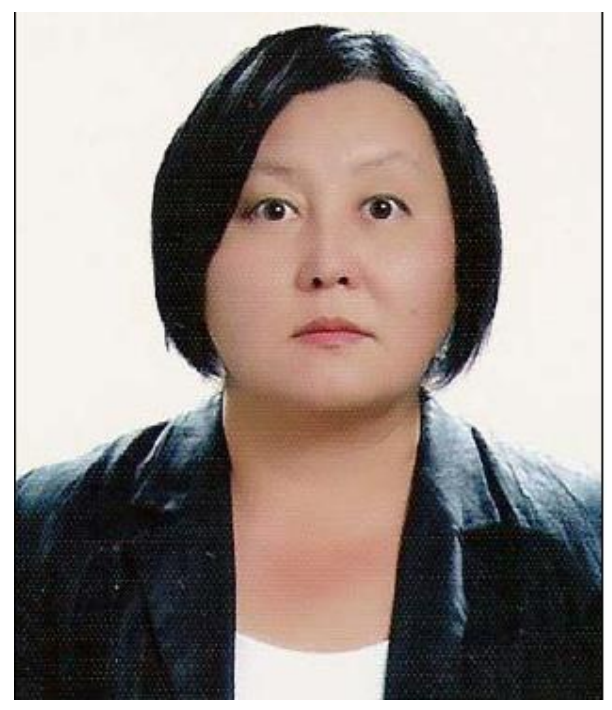

Dear Readers

In this issue, we published the editorial about prominent surgeon, founder of cardiovascular surgery in Central Asia who performed first heart surgery - Professor Isa K. Akhunbaev. In every further issue of the journal in frame of the $60^{\text {th }}$ anniversary of cardiac surgery and $15^{\text {th }}$ anniversary of SRI of Heart Surgery and Organ Transplantation in Kyrgyzstan, we plan to publish interviews with surgeons, anesthesiologists and other specialists who were members of the first heart surgery team contributed to the development of cardiovascular surgery.

You can also find research article, interesting case report, quiz on electrophysiology, and reports on arrhythmia school in Bishkek and on research school in Baet, Issyk-Kul, we mentioned about this school in June issue.
We look forward for your articles, reviews, case reports and images, interviews and historical notes, articles on innovative methods. Your feedback in form of letters to the editor as readers is vitally important for us.

We updated aims and scope and instructions for authors. Our multidisciplinary journal will also consider for publication the articles having regional and international importance.

Gulmira Kudaiberdieva Editor-in-Chief Heart Vessels and Transplantation

Peer-review: internal

Conflict of interest: None to declare Authorship: G.K.

Acknowledgement and funding: None to declare

Address for Correspondence: Gulmira Kudaiberdieva, Editor-in-Chief, Heart Vessels and Transplantation, email: editor@hvt-journal.com

Received 30.08.2018 Accepted 31.08.2018

Copyright $\odot$ Heart Vessels and Transplantation doi: 10.24969/hvt.2018.78 